\title{
THE EFFICACY OF COMBINATION THERAPY WITH LENALIDOMIDE AND DEXAMETHASONE IN THE TREATMENT OF RELAPSED MULTIPLE MYELOMA
}

\author{
Aneta Szudy-Szczyrek ${ }^{1}$, Wojciech Legiećc ${ }^{1}$, Joanna Mańko ${ }^{1}$, \\ Katarzyna Gmyz ${ }^{1}$, Michał Szczyrek ${ }^{2}$, Marek Hus ${ }^{1}$ \\ ${ }^{1}$ Chair and Department of Haematooncology and Bone Marrow Transplantation, Medical University of Lublin \\ ${ }^{2}$ Chair of Internal Medicine and Department of Internal Medicine in Nursing, Medical University of Lublin
}

Szudy-Szczyrek A., Legieć W., Mańko J., Gmyz K., Szczyrek M., Hus M. (2015), The efficacy of combination therapy with lenalidomide and dexamethasone in the treatment of relapsed multiple myeloma. Health Problems of Civilization, 2 (9), p. 50-54.

Summary: Multiple myeloma is a neoplastic disease which is characterised by proliferation of monoclonal plasmocytes in the bone marrow. It is the second most common hematologic cancer and it represents $1 \%$ of all cancer deaths. Despite enormous development in multiple myeloma biology and treatment over the last 30 years - it is still incurable disease with a median survival of 50 - 55 months. Currently, one of the most important goals in the treatment of multiple myeloma is to achieve long-term control of the disease, without negative impact on the patient's quality of life. Thanks to therapeutic regimens based on new immunomodulatory drugs, this aim seems to be achievable. In this paper we present the case of a female patient living with multiple myeloma for 14 years. Initially patient was treated with standard VAD (vincristine, doxorubicin, dexamethasone) chemotherapy regimen. After a nearly complete remission of the disease, autotransplantation of hematopoietic cells was performed. One year after transplantation there was a relapse of the disease. In the treatment of relapse it was decided to use scheme based on lenalidomide and dexamethasone. After $4^{\text {th }}$ cycle of treatment, a complete remission was achieved. So far, the patient received 149 cycles. In the evaluation of minimal residual disease still maintains a state of complete remission maintains. During over 12 years of treatment no complications in grade 3 and 4 of the CTCAE v.4 was observed. Currently the patient is 58 years old, she still receives lenalidomide and leads moderately active life.

Keywords: multiple myeloma, immunomodulatory drugs, maintenance therapy, lenalidomide

\section{Introduction}

Despite enormous development in the therapy, and introduction of high-dose chemotherapy treatment with autologous bone-morrow stem-cell transplantation (ASCT) in 1990's, plasmocytoma is still a disease in which permanent cure is not possible in case of most patients (Kumar et al. 2008). Among almost all patients after ASCT relapse occurs, and the median progression free survival (PFS) is approximately 2-3 years (Attal et al. 1996; Child et al. 2003). Currently, the maintenance therapy is one of the most important points of treatment for multiple myeloma. Due to new therapeutic regimens based on the immunomodulatory drugs - lenalidomide and bortezomib, it seems to be possible to achieve long-term control of the disease, to prolong overall time of survival and progression free survival (PFS), without negative effects on patient's quality of life.

Lenalidomide is the first immunomodulatory drug, which was approved for the treatment of patients with relapsed or refractory multiple myeloma. It belongs to the group of oral immunomodulatory drugs, it is analogue of thalidomide, with significantly stronger effect, and preferred profile of toxicity. Lenalidomide has dual mechanism of action: antitumor activity leads to tumor cell death, immunomodulatory activity affectes the function of the immune system. It directly induces apoptosis of tumor cells, has antiangiogenic activity, removes the protection of the marrow microenvironment towards tumor cells and stimulates antitumor resistance of the host, allowing to maintain the suppression of tumor (Davies et al. 2001, Gupta et al. 2001, Mitsiades et al. 2002).

Address for correspondence: Aneta Szudy-Szczyrek, Staszica 11, 20-081 Lublin, phone: +48 81 534 54 68, e-mail: anetaszudy@gmail.com Tables: 0 Figures: 5 References: 12 Full-text PDF www.hpc.edu.pl Copyright C) Pope John Paul II State School of Higher Education in Biała Podlaska, Sidorska 95/97, 21-500 Biała Podlaska Indexation: Index Copernicus, AGR0, ProQuest, Polish Medical Bibliography, Polish Ministry of Science and Higher Education. This is an open-access article distributed under the terms of the Creative Common Attribution Non-commercial license (http://creativecommons.org/licenses/by-nc/3.0), which permits use, distribution and reproduction in any medium, provided the original works is properly cited, the use is non-commercial and is otherwise in compliance with the license. 
In this paper we present the case history of a patient with multiple myeloma. In a relapse, after the autologous bone-morrow stem-cell transplantation (ASCT), patient received lenalidomide and dexamethasone in a clinical trial CC-5013-MM-010. With the used treatment, a long-term complete remission of the disease was obtained, which continues till now, for over 12 years.

\section{Case study}

The female patient at time of the diagnosis of multiple myeloma was 44 years old (April 2000). The first clinical symptoms were weakness, decrease in exercise tolerance and severe bone pain. In laboratory studies there was profound anaemia (HGB $7.1 \mathrm{~g} / \mathrm{dL}$ ), high ESR - 120mm/hr and a high total protein concentration 12 $\mathrm{g} / \mathrm{dL}$. In medical imaging studies, osteolytic abnormalities were present in Th spine section. After additional examination multiple myeloma IgG kappa stage III (classification of Durie-Salmon) was diagnosed.

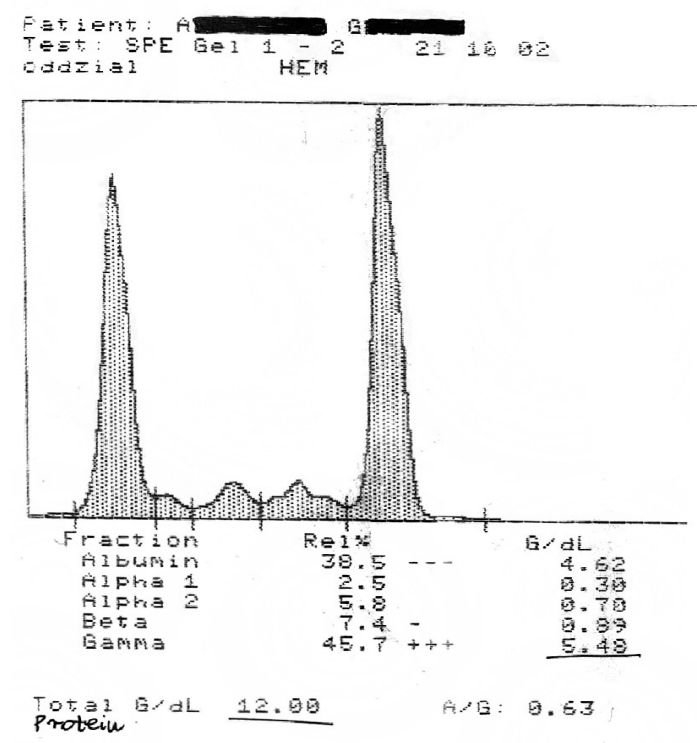

Figure 1. Plasma proteins electrophoresis results

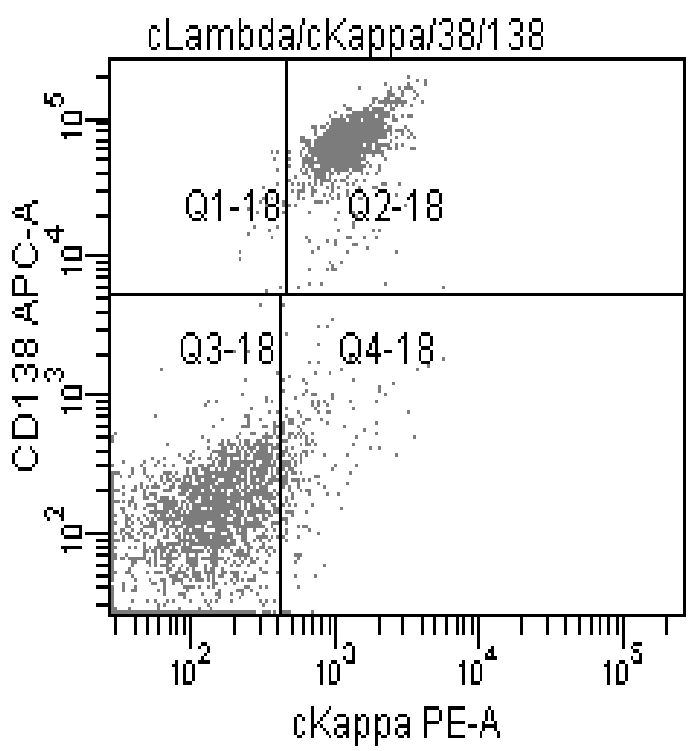

Figure 2. Evaluation of the neoplastic plasmocytes by flow cytometry analysis obtained during the diagnosis

Patient was qualified to VAD (vincristine, doxorubicin, dexamethasone) chemotherapy. She was receiving medications in due doses with good tolerance. Bisphosphonates were also used in the treatmant. During chemotherapy there were no adverse events. After 7 cycles of VAD, there were features of almost complete remission, and the patient was qualified for autologous peripheral stem cell transplant (autoPSCT).

In order to mobilize stem cells, patient received 3,5g/m2 of cyclophosphamide. Two apheresis procedures of stem cells were performed with a result yield $9.54 \times 10^{\wedge} 6$ CD $34+$ cells per kilogram of body weight. AutoPSCT was performed on $1^{\text {st }}$ March 2001, after conditioning with Mel200 system, 11 months after the diagnosis of multiple myeloma. Period of transplantation and aplasia after transplantation was without any adverse events. In $+13^{\text {th }}$ day features of hematopoietic recovery were found ANC $>0.5 \mathrm{G} / \mathrm{l}$, PLT $>50 \mathrm{G} / \mu \mathrm{l}$. In control bone marrow biopsy at day +100 after autoPSCT, complete remission of the disease was confirmed.

After 12 months of observation in an outpatient conditions, characteristics of a relapse were found in the form of re-apperance of monoclonal protein IgG kappa $9.04 \mathrm{~g} / \mathrm{dL}$. 


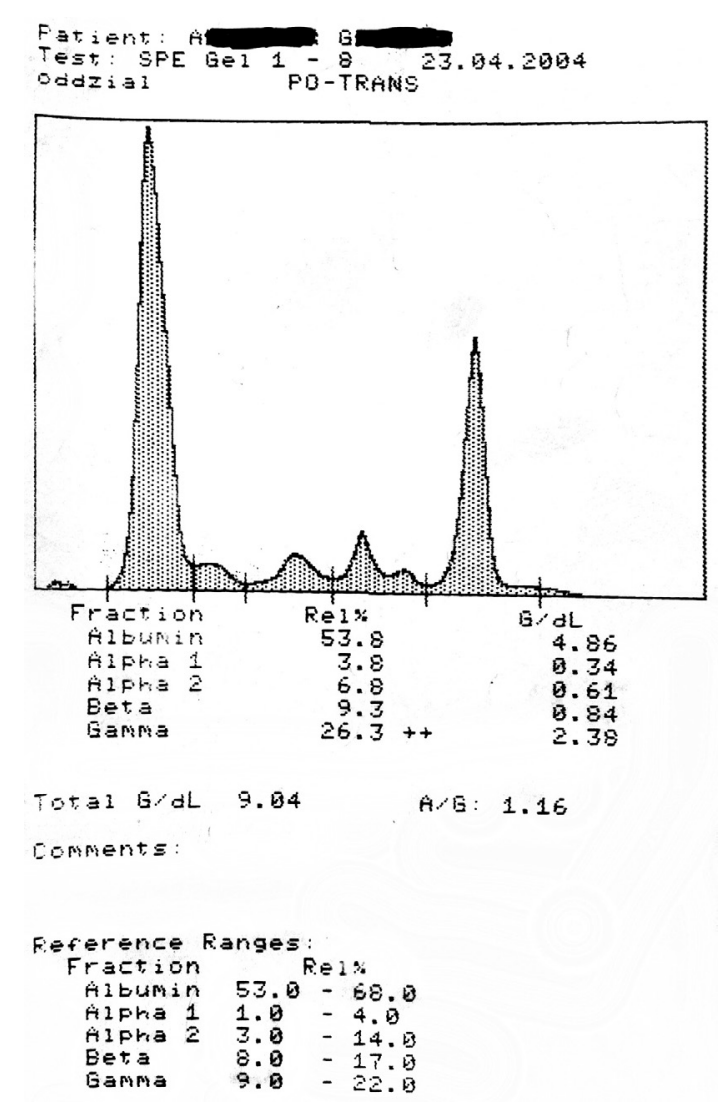

Figure 3. Results of plasma proteins electrophoresis, 12 months after ASCT- recurrence of the disease

In the treatment of relapse of the disease, patient was enrolled in clinical trial CC-5013-MM-010 with lenalidomide and dexamethasone. Treatment was started in April 2002. Drugs were used according to 28-day regimen: lenalidomide $25 \mathrm{mg} / \mathrm{d}$ - days 1.-21; dexamethasone $40 \mathrm{mg} / \mathrm{d}$ - days 1.-4.; 9.-12.; 17.-20. in cycles 1 - 4; dexamethasone $40 \mathrm{mg} / \mathrm{d}$ - days $1 .-4$. after cycle 4 th.

After 4 cycles of treatment a complete remission of the neoplasm was obtained. Until August 2014 the patient received 149 cycles of treatment. Until October 2011, the patient was receiving lenalidomide in a clinical trial, since then the patient still continues treatment outside the clinical trial, thanks to the trial sponsor. From 96th cycle of the chemotherapy the decision was made to gradually reduce steroids doses, in November 2011 dexamethasone treatment was stopped. In January 2013 the dose of lenalidomide was also reduced to $10 \mathrm{mg} / 21$ days.

During over 12 years of treatment no adverse effects in grade 3 or 4 by CTCAE v.3. were noted. Patient has a long history of coping with multiple myeloma, she lives moderately active life. In August 2014 her performance status was evaluated as 0 according to ECOG scale.

The evaluation of minimal residual disease in May 2014 confirmed complete remission of the disease; monoclonal plasmocytes evaluated by flow cytometry in the bone marrow represent $0.61 \%$, in bone biopsy and in bone marrow aspiration no plasmocytes were found. No monoclonal protein was found in plasma protein immunofixation, and no features of the bone progression were noted. 


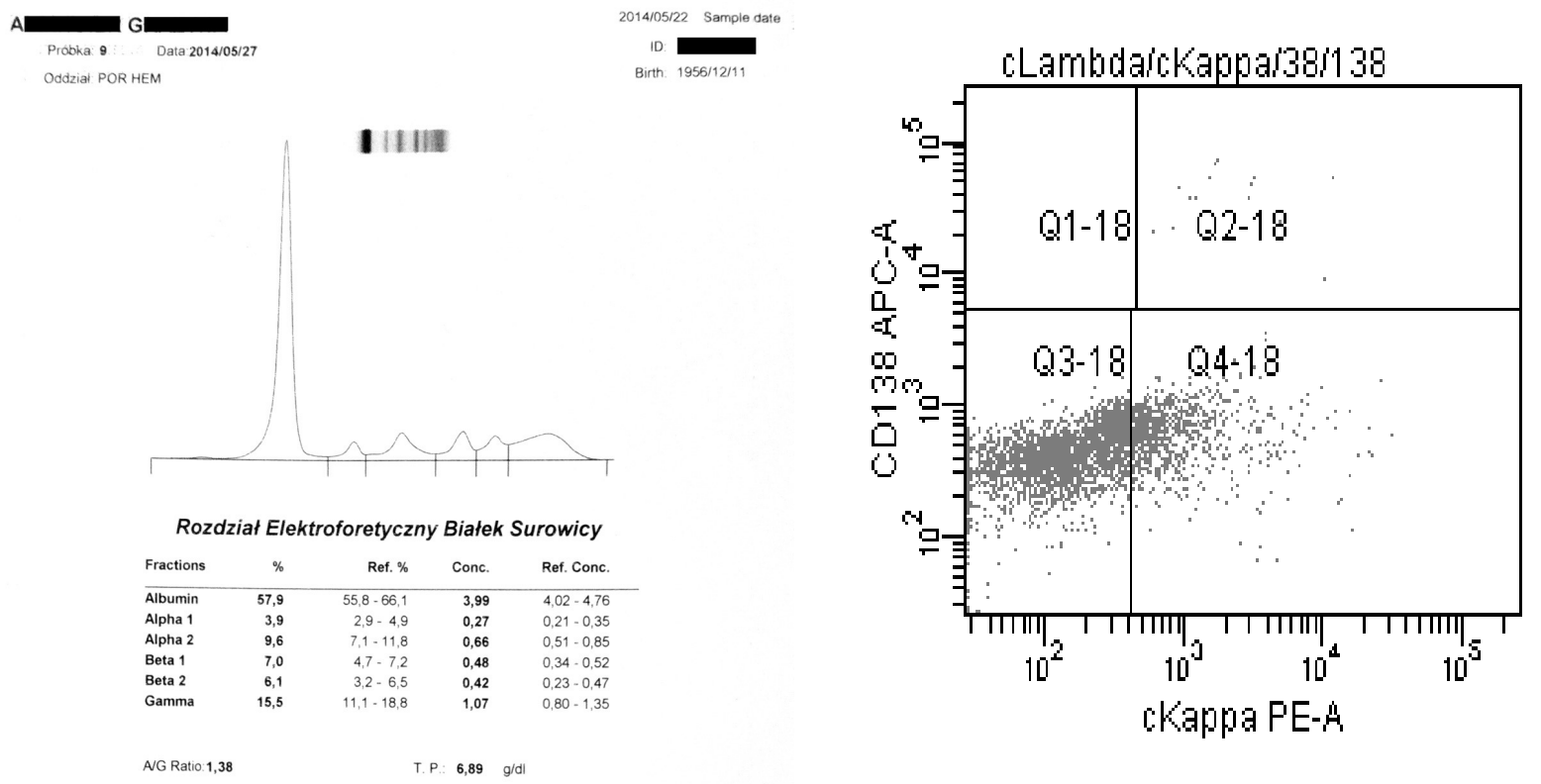

Figure 4-5. Evaluation of the minimal residual disease assessed by the flow cytometry method and electrophoresis results of plasma proteins

\section{Discussion}

Lenalidomide in combination with dexamethasone was registered in the United States in 2006 for the treatment of patients with relapsed or refractory multiple myeloma, based on results of two major randomized phase III clinical trials conducted in United States and in Europe (MM-009 and MM-010 respectively). In total 704 patients took part in those trials i.e. about 350 patients in each trial. The aim of the study was to compare the efficacy and safety of using lenalidomide in combination with dexamethasone and dexamethasone in monotherapy in patients with relapsed, refractory multiple myeloma. In the group of patients receiving combination therapy a higher percentage of overall response rate (ORR 60.6\% vs. 21.9\%, p <0.001) and a longer duration of response (15.8 months vs 7 months, $\mathrm{p}<0.001$ ) was achieved (Dimopoulos et al. 2007, Weber et al. 2007). Longer time to progression (TTP 13.4 vs 4.6 months, $\mathrm{p}<0.001$ ) and prolonged overall survival (OS 38.0 vs 31.6 months, $\mathrm{p}=0.045$ ) was obtained compared to the group of patients receiving dexamethasone and placebo (Dimopoulos et al. 2009). Lenalidomide in combination with dexamethasone allow to obtain fast and clinically significant responses, which improve further during the treatment (Harousseau et al. 2010). Continuation of the therapy after gaining the first response significantly increased the survival of the patients (San-Miguel et al. 2011). Among patients treated with lenalidomide and dexamethasone reaching at least a partial response (PR) and continuing the treatment - twothirds of people (108/174) still received treatment after a median of clinical observation period (48.6 months). In patients who continued combination therapy until disease progression, a trend to prolong the OS was noted, when compared to those who interrupted the treatment for reasons other than progression $(\mathrm{p}=0.0594)$.

In the studies MM-009 and MM-010 an acceptable safety profile of lenalidomide was observed. The most common adverse events of the drug were: fatigue, neutropenia, constipation, diarrhea, muscle cramps, anaemia, thrombocytopenia and rash. The most observed adverse events in grade 3 and 4 were thrombocytopenia, neutropenia and thromboembolic events. Most events were observed during the first 3 months of treatment. The incidence of peripheral neuropathy among patients receiving lenalidomide was $1.4 \%$. The incidence of thromboembolic events was higher in lenalidomide and dexamethasone group in the absence of prophylactic anticoagulant than in group with dexamethasone $(\mathrm{P}<0,001)$. Dosing was associated with minimal cumulative toxicity, making possible to use long-term treatment (Dimopoulos et al. 2009).

The results of studies MM-009 and MM-010 concurred with conclusion presented in the summary of MM-018 study by Spanish group of researchers (Alegre et al. 2012). Study included 63 adults patients with the multiple myeloma progression after $>=2$ cycles of chemotherapy. Treatment with lenalidomide and dexamethasone was associated with a high ORR (78\%), median TTP (13.3 months), median PFS (13.3 months). Median of OS (overall survival) was not reached (95\%CI: indefinite). A higher percentage of patients continuing the treatment $>=12$ cycles showed VGPR or CR when compared with patients who finished therapy before 12th cycle. The continuation of treatment until occurence of VGPR or CR was associated with a deeper and more permanent clinical remission 
and improvement of PFS and OS in comparison with patients who reached PR. Serious adverse events of grade 3 and 4 were observed in $5 \%$ of patients. It included mainly myelosuppression, which was treated by a appropriate dose reduction of lenalidomide and dexamethasone. Authors also observed: hyperglycemia, thromboembolic events, infections of the respiratory system and asthenia. 17\% (11 patients) stopped treatment due to AE.

\section{Conclusion}

In retrospective data analysis from the clinical trials MM-010, MM-009, MM-018 the positive effect of longterm treatment using lenalidomide in combination with dexamethasone in patients with relapsed multiple myeloma was confirmed. Case study of a female patient with complete remission of the disease, undoubtly provide excellent proof of the efficacy as well as safety of maintenance therapy of this type.

\section{References:}

1. Alegre A., Oriol-Rocafiguera A., Garcia-Larana J., Mateos M.V., Sureda A., Martinez-Chamorro C., Cibeira M.T., Aguado B., Knight R., Rosettani B. (2012), Efficacy, safety and quality-of-life associated with lenalidomide plus dexamethasone for the treatment of relapsed or refractory multiple myeloma: the Spanish experience. Leuk Lymphoma; 53:1714-21.

2. Attal M., Harousseau J.L., Stoppa A.M., Sotto J.J., Fuzibet J.G., Rossi J.F., Casassus P., Maisonneuve H., Facon T., Ifrah N., Payen C., Bataille R. (1996), A prospective, randomized trial of autologous bone marrow transplantation and chemotherapy in multiple myeloma. Intergroupe Français du Myélome. N Engl J Med.; 335: 91-7.

3. Child J.A., Morgan G.J., Davies F.E., Owen R.G., Bell S.E., Hawkins K., Brown J., Drayson M.T., Selby P.J., Medical Research Council Adult Leukaemia Working Party. (2003), High-dose chemotherapy with hematopoietic stemcell rescue for multiple myeloma. N Engl J Med.; 348: 1875-83.

4. Davies F.E., Raje N., Hideshima T., Lentzsch S., Young G., Tai Y.T., Lin B., Podar K., Gupta D., Chauhan D., Treon S.P., Richardson P.G., Schlossman R.L., Morgan G.J., Muller G.W., Stirling D.I., Anderson K.C. (2001), Thalidomide and immunomodulatory derivatives augment natural killer cell cytotoxicity in multiple myeloma. Blood; 98: 210-216.

5. Dimopoulos M., Spencer A., Attal M., Prince H.M., Harousseau J.L., Dmoszynska A., San Miguel J., Hellmann A., Facon T., Foà R., Corso A., Masliak Z., Olesnyckyj M., Yu Z., Patin J., Zeldis J.B., Knight R.D.; Multiple Myeloma (010) Study Investigators. (2007), Lenalidomide plus dexamethasone for relapsed or refractory multiple myeloma. N Engl J Med.; 357: 2123-32.

6. Dimopoulos M.A., Chen C., Spencer A., Niesvizky R., Attal M., Stadtmauer E.A., Petrucci M.T., Yu Z., Olesnyckyj M., Zeldis J.B., Knight R.D., Weber D.M. (2009), Long-term follow-up on overall survival from the MM-009 and MM-010 phase III trials of lenalidomide plus dexamethasone in patients with relapsed or refractory multiple myeloma. Leukemia; 23: 2147-52.

7. Gupta D., Treon S.P., Shima Y., Hideshima T., Podar K., Tai Y.T., Lin B., Lentzsch S., Davies F.E., Chauhan D., Schlossman R.L., Richardson P., Ralph P., Wu L., Payvandi F., Muller G., Stirling D.I., Anderson K.C. (2001), Adherence of multiple myeloma cells to bone marrow stromal cells upregulates vascular endothelial growth factor secretion: therapeutic applications. Leukemia; 15: 1950-61.

8. Harousseau J.L., Dimopoulos M.A., Wang M., Corso A., Chen C., Attal M., Spencer A., Yu Z., Olesnyckyj M., Zeldis J.B., Knight R.D., Weber D.M. (2010), Better quality of response to lenalidomide plus dexamethasone is associated with improved clinical outcomes in patients with relapsed or refractory multiple myeloma. Haematologica; 95: 1738-44.

9. Kumar S.K., Rajkumar S.V., Dispenzieri A., Lacy M.Q., Hayman S.R., Buadi F.K., Zeldenrust S.R., Dingli D., Russell S.J., Lust J.A., Greipp P.R., Kyle R.A., Gertz M.A. (2008), Improved survival in multiple myeloma and the impact of novel therapies. Blood; 111: 2516-20.

10. Mitsiades N., Mitsiades C.S., Poulaki V., Chauhan D., Richardson P.G., Hideshima T., Munshi N.C., Treon S.P., Anderson K.C. (2002), Apoptotic signaling induced by immunomodulatory thalidomide analogs in human multiple myeloma cells: therapeutic implications. Blood; 99: 4525-30.

11. San-Miguel J.F., Dimopoulos M.A., Stadtmauer E.A., Rajkumar S.V., Siegel D., Bravo M.L., Olesnyckyj M., Knight R.D., Zeldis J.B., Harousseau J.L., Weber D.M. (2011), Effects of lenalidomide and dexamethasone treatment duration on survival in patients with relapsed or refractory multiple myeloma treated with lenalidomide and dexamethasone. Clin Lymphoma Myeloma Leuk.; 11: 38-43.

12. Weber D.M., Chen C., Niesvizky R., Wang M., Belch A., Stadtmauer E.A., Siegel D., Borrello I., Rajkumar S.V., ChananKhan A.A., Lonial S., Yu Z., Patin J., Olesnyckyj M., Zeldis J.B., Knight R.D.; Multiple Myeloma (009) Study Investigators. (2007), Lenalidomide plus dexamethasone for relapsed multiple myeloma in North America. N Engl J Med.; 357: $2133-42$. 